\title{
EDUCAÇÃO AMBIENTAL NA PERCEPÇÃO DE DOCENTES PEDAGOGOS DO ENSINO FUNDAMENTAL
}

\author{
ENVIRONMENTAL EDUCATION IN THE PERCEPTION \\ OF TEACHERS OF ELEMENTARY SCHOOL \\ EDUCACIÓN AMBIENTAL EN LA PERCEPCIÓN DE
PROFESORES DOCENTES DE EDUCACIÓN PRIMARIA
}

Lia Machado Fiuza Fialho ${ }^{\text {I }}$
NaARa CAMPelo Rodrigues ${ }^{\text {II }}$

Francisca Genifer Andrade de Sousa III

${ }^{\mathrm{I}}$ Universidade Estadual do Ceará (UECE), Fortaleza/CE, Brasil

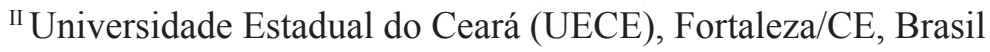

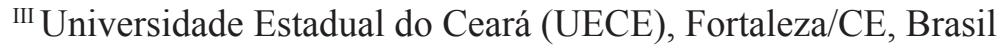

RESUMO Objetivou-se compreender o que os educadores do ensino fundamental entendem por educação ambiental e quais atividades pedagógicas desenvolvem para trabalhar esse campo do conhecimento. Realizou-se uma pesquisa, qualitativa, do tipo estudo de caso, que utilizou entrevistas semiestruturadas como instrumento de coleta de dados. Participaram 20 professores de uma Escola Municipal, localizada no bairro Jangurussu, na periferia de Fortaleza-CE. Os resultados, submetidos à análise de conteúdo, foram discutidos a partir das três categorias emergentes: 1) formação inicial em educação ambiental; 2) práticas em educação ambiental; 3) formação continuada e atualização sobre educação ambiental. A formação inicial em nível de graduação mostrou-se incipiente quanto à instrumentalização dos professores na abordagem da educação ambiental em sala de aula, pois os cursos superiores não possuíam essa disciplina como obrigatória em seus currículos e não trabalhavam transversalmente os conhecimentos de educação ambiental; a formação continuada, ofertada pela prefeitura de Fortaleza, também não abordava esse conhecimento. Consoante uma temática relegada a segundo plano de importância, as práticas pedagógicas em educação ambiental eram fragilizadas e fragmentadas, impossibilitando desenvolver uma consciência ambiental comprometida com a transformação social.

Palavras-chave: EducaÇão ambiental; Práxis educativa; Ensino fundamental; JanGURUSSU. 
ABSTRaCr The objective was to understand what elementary school educators understand by environmental education and what pedagogical activities they develop to work in this field of knowledge. A qualitative, case study research was carried out, which used semistructured interviews as a data collection instrument. Twenty teachers from the Municipal school, located in the Jangurussu neighborhood, on the outskirts of Fortaleza-CE, participated. The results, submitted to content analysis, were discussed from the three emerging categories: 1) initial training in environmental education; 2) practices in environmental education; 3) ongoing training and updating on environmental education. Initial training at undergraduate level proved to be incipient in terms of instructing teachers to approach environmental education in the classroom, as higher education courses did not have this subject as mandatory in their curricula and did not work across environmental education knowledge; continuing education, offered by the city of Fortaleza, also did not address this knowledge. Depending on a theme that is relegated to a second level of importance, pedagogical practices in environmental education were weakened and fragmented, making it impossible to develop an environmental awareness committed to social transformation.

Keywords: EnVironmental education; Educational praxis; Elementary School; JANGURUSSU.

RESUMEN El objetivo era comprender qué entienden los educadores de primaria por la educación ambiental y qué actividades pedagógicas desarrollan para trabajar en este campo del conocimiento. Se realizó una investigación cualitativa de estudio de caso, que utilizó entrevistas semiestructuradas como instrumento de recopilación de datos. Participaron veinte docentes de una Escuela Municipal, ubicada en el barrio de Jangurussu, en las afueras de Fortaleza-CE. Los resultados, sometidos a análisis de contenido, se discutieron en las tres categorías emergentes: 1) capacitación inicial en educación ambiental; 2) prácticas en educación ambiental; 3) capacitación y actualización continua sobre educación ambiental. La capacitación inicial a nivel de pregrado demostró ser incipiente en términos de instruir a los maestros para que aborden la educación ambiental en el aula, ya que los cursos de educación superior no tenían este tema como obligatorio en sus planes de estudio y no funcionaban en el conocimiento de la educación ambiental; La educación continua, ofrecida por la ciudad de Fortaleza, tampoco abordó este conocimiento. Dependiendo de un tema que se relega a un segundo nivel de importancia, las prácticas pedagógicas en educación ambiental se debilitaron y fragmentaron, haciendo imposible desarrollar una conciencia ambiental comprometida con la transformación social.

Palabras clave: Educación ambiental; Praxis educativa; Educación primaria; JanGURUSSU.

\section{INTRODUÇÃo}

O artigo trata da Educação Ambiental (EA) compreendendo-a como a gestão qualificada do ambiente, ao primar pela participação dos indivíduos no gerenciamento dos lugares onde vivem e interagem - casa, escola, rua, bairro, cidade etc. - ou seja, "a Educação 
Ambiental de conteúdo emancipatório e transformador é aquela em que a dialética forma e conteúdo realizam-se de tal maneira que as alterações da atividade humana, vinculadas ao fazer educativo, impliquem mudanças individuais e coletivas" (LOUREIRO, 2005, p. 1.484). Como o seu principal objetivo é contribuir para a postura responsável de interação com o meio ambiente, deve-se, por essa razão, pensar o currículo escolar e as práticas empreendidas no sentido de promover a conscientização com vistas ao cuidado com o ambiente e convívio harmônico (GUEDES, 2006).

A EA, por sua importância, é mencionada na legislação educacional brasileira, especificamente na Lei de Diretrizes e Bases (LDB), Lei no . 9.394/96, no artigo 32, inciso II, que, ao abordar sobre as competências do Ensino Fundamental, lista a "compreensão ambiental natural e social do sistema político, da tecnologia, das artes e dos valores em que se fundamenta a sociedade" (BRASIL, 1996, p. 23). Na mesma direção, as Diretrizes Curriculares Nacionais (DCN), que tratam a respeito dos temas transversais no Ensino Fundamental, defendem que a EA admite a possibilidade de reorganização das práticas pedagógicas com vistas a fomentar a formação cidadã e consciente do indivíduo com o seu meio, de forma a diminuir os impactos da degradação do ser humano no meio ambiente (BRASIL, 1998). A escola, como lócus de formação, é espaço privilegiado para estimular posturas cidadãs responsáveis com o meio ambiente, devendo despertar nos estudantes o sentimento de pertencimento ao seu meio, para que possam assumir, de maneira crítica, a tarefa de zelar por ele (FRIEDE; REIS; AVELAR; MIRANDA, 2019).

Haja vista que as instituições de educação formal são importantes espaços para o desenvolvimento de valores e atitudes compromissadas com a sustentabilidade ecológica e social (LIMA, 2004; PINHEIRO; SANTOS; PELUC, 2017), ao refletir sobre as especificidades da EA na inter-relação com a escolarização formal, surgiram algumas inquietações que instigaram este estudo: O que os professores pedagogos do Ensino Fundamental entendem por EA? Como as formações inicial e/ou continuada contribuem para a qualificação do trabalho pedagógico com essa temática? Como esses professores desenvolvem as atividades didáticas com o objetivo de desenvolver a consciência ambiental?

Para explanar tais problemáticas, desenvolveu-se uma pesquisa com o objetivo de compreender o que os professores do Ensino Fundamental entendem por educação ambiental e quais atividades pedagógicas desenvolvem para trabalhar esse campo do conhecimento. Importa destacar que o estudo dialoga com as narrativas de docentes licenciados em Pedagogia, que lecionam na primeira etapa do Ensino Fundamental na modalidade polivalente, ou seja, assumindo a responsabilidade por trabalhar os conteúdos de todas as disciplinas.

A escola lócus do estudo, localizada no bairro Jangurussu, região periférica da capital cearense, foi selecionada porque além de apresentar abertura necessária para a realização do estudo, é situada próxima ao local onde foi destinado, durante 20 anos, todo o lixo produzido em Fortaleza, a céu aberto, prática atualmente extinta, mas que deixou sequelas naquele entorno. Gonçalves (2006) informa que o local chegou a abrigar em seus arredores cerca de 1.500 catadores de lixo, que buscavam material reciclável e restos de alimentos, população que foi constituindo residência no referido bairro.

A poluição ambiental no Jangurussu, especialmente do solo e das águas, ainda demanda atenção específica quanto à preservação do meio ambiente na região (CAVALCANTE, 
et al., 2011), já que o bairro, até hoje, é conhecido pela histórica receptação de lixo, acarretando, inclusive, estigma para os residentes do bairro (IZAIAS, 2010). Os moradores do Jangurussu carecem de EA de maneira mais enfática, pois precisam enfrentar tanto as condições ambientais degradadas, como o preconceito por serem moradores de uma localidade periférica, poluída e pouco valorizada no âmbito da especulação imobiliária.

A relevância do estudo justifica-se pela possibilidade de ampliar a compreensão no que diz respeito às nuanças que compreendem a EA, não apenas na realidade de uma escola pública municipal de Fortaleza-CE, pois os estudos de caso, ainda que trabalhem com a escala microssocial, estão inseridos num contexto macrossocial, o que oportuniza tecer reflexões e discussões que envolvem assuntos específicos e gerais relacionados às compreensões e às práticas docentes com foco na EA, tais como a formação dos professores para o trato com essa temática, a atualização dessa categoria para abordar o assunto em tela, as práticas pedagógicas desenvolvidas etc.

O artigo foi subdividido em quatro seções: a primeira, denominada introdução, apresenta a temática do estudo, o objetivo da pesquisa, o objeto de estudo - as narrativas dos professores - e a relevância do estudo; a segunda, denominada metodologia, explicita o percurso investigativo utilizado para desenvolver o estudo, explicando a escolha da abordagem, do tipo de estudo, dos sujeitos participantes, do instrumento de coleta de dados e da sua análise; a terceira, resultados e discussão, parte das narrativas dos professores para discutir a compreensão acerca da EA e as práticas mobilizadas para promover a EA; a última, considerações finais, retoma o objetivo central para respondê-lo de maneira concisa, demonstrando os principais achados da pesquisa e as limitações do estudo.

\section{Metodologia}

O estudo caracteriza-se pela abordagem qualitativa (MINAYO, 1994), pois considera as subjetividades dos professores de uma instituição pública, valorizando as suas percepções e lançando luz às subjetividades invisibilizadas em pesquisas macrossociais. Muitos estudiosos desenvolvem pesquisas qualitativas e advogam sua relevância (DINARTE; CORAZZA, 2016; MORGADO, 2016; LIMA; SANTOS, 2018), já que estas possibilitam análises mais sensíveis de contextos específicos.

A pesquisa é do tipo estudo de caso único, pois considerou a realidade vivenciada pelo corpo docente de uma única escola pública municipal de Fortaleza-CE, essa instituição concedeu anuência ao desenvolvimento do estudo mediante o consentimento da coordenadora da educação infantil, que inclusive acompanhava os pesquisadores e os apresentava aos professores colaboradores para efetivação do convite pessoalmente. Tal escolha é amparada por Yin (2001, p. 32), que enfatiza a importância dos estudos de caso por se tratar de "uma investigação empírica que investiga um fenômeno contemporâneo dentro do seu contexto da vida real, especialmente quando os limites entre o fenômeno e o contexto não estão claramente definidos", o que faculta uma investigação qualitativa mais aprofundada.

A coleta dos dados foi realizada mediante entrevista semiestruturada para sondagem das compreensões e das experiências docentes, apontando limites e possibilidades que perpassavam o desenvolvimento da EA em meio ao currículo formal. Ao total, foram contata- 
dos todos os 22 professores de uma escola pública municipal de Fortaleza, escolhidos por serem pedagogos e atuarem na primeira etapa do ensino fundamental. Desses, 20 deram retorno positivo, concordando em participar, após leitura e explicação do Termo de Compromisso Livre e Esclarecido (TCLE). Os outros dois professores alegaram falta de tempo e de interesse em colaborar.

Importa ressaltar que os vinte professores participaram do estudo de forma voluntária, após a assinatura do TCLE, que esclareceu a temática da pesquisa, o objetivo do estudo, a forma de participação, a possibilidade de desistir a qualquer momento, a inexistência de prejuízos e benefícios, a garantia de preservação da identidade, a utilização dos dados para fins de pesquisa científica, a possibilidade de divulgação do estudo em eventos ou periódicos científicos etc. Em decorrência de o anonimato ter sido assegurado, seguindo os critérios éticos estipulados pela resolução $\mathrm{n}^{\circ}$. 466, de 12 de dezembro de 2012, do Conselho Nacional de Saúde, no que concerne às pesquisas realizadas com seres humanos, as identidades dos colaboradores foram preservadas e eles foram renomeados por Professor 1 (P1); Professor 2 (P2), P3, P4, P5, e assim sucessivamente, seguindo a ordem em que se procederam as entrevistas para identificação. Todas as entrevistas foram realizadas, transcritas e textualizadas, no decorrer do mês de abril de 2016, no ambiente de trabalho dos docentes.

A entrevista semiestruturada foi composta por cinco indagações norteadoras: 1) $\mathrm{Na}$ sua formação inicial, no curso de Pedagogia, havia alguma disciplina sobre educação ambiental? Em caso positivo, você cursou? 2) O que você compreende por educação ambiental? 3) Você aborda a educação ambiental em suas aulas? Em caso positivo, de qual maneira? 4) Como você avalia a importância de a educação ambiental ser trabalhada nas escolas de educação básica? e 5) Você já participou de alguma atualização/formação continuada que tratou sobre a educação ambiental?

A análise das respostas e a discussão dos resultados procederam conforme os ensinamentos de Bardin (2006), no que diz respeito à análise de conteúdo. Logo, primeiro foi realizada a leitura flutuante, que consiste na leitura e releitura cuidadosa do material coletado; seguida da pré-análise para apreensão dos assuntos mais recorrentes, culminando na codificação e na categorização, por meio das quais as informações afins foram agrupadas em categorias, que por sua vez "reúnem um grupo de elementos [...] sob um título genérico, agrupamento esse efetuado em razão dos caracteres comuns destes elementos" (BARDIN, 2006, p. 117). Para isso, foram adotados critérios específicos: foram agregadas todas as informações semelhantes das entrevistas; agrupados os construtos que mais se assemelhavam e, por fim, reunidas as temáticas em grupos, que facilitaram a organização das discussões. O quadro, a seguir, explicita esse processo, apresentando os grupos temáticos emergentes (à esquerda) e as informações afins (à direita) das narrativas que os compuseram, esclarecendo os assuntos elencados pelos entrevistados acerca de cada uma das temáticas. 
Quadro 1 - Grupos temáticos e descritores

\begin{tabular}{|c|c|}
\hline Grupos temáticos & Descritores \\
\hline Formação inicial & $\begin{array}{c}\text { Graduação. Pedagogia. Educação Ambiental. } \\
\text { Disciplina optativa. Disciplina obrigatória. Currículo } \\
\text { acadêmico }\end{array}$ \\
\hline Prática pedagógica & $\begin{array}{c}\text { Formação integral. Prática em sala de aula. Livro } \\
\text { didático. Material didático. Fragmentos de atividades. } \\
\text { Ciências da Natureza. Reciclagem. Tema transversal. }\end{array}$ \\
\hline $\begin{array}{c}\text { Formação continuada e atualização } \\
\text { profissional }\end{array}$ & $\begin{array}{c}\text { Formação insuficiente. Palestra. Curso. Iniciativa } \\
\text { individual. Formação semanal. Prefeitura de Fortaleza. }\end{array}$ \\
\hline
\end{tabular}

Fonte: Autoria própria (2020).

Portanto, as narrativas foram analisadas criteriosamente e agrupadas a partir de um termo aglutinador que contemplasse os discursos similares entre si, de modo que foram unificados os assuntos relacionados à formação inicial, à prática pedagógica e à formação continuada em educação ambiental, processo que finalizou com a categorização, última etapa da análise de conteúdo.

\section{RESULTADOS E DISCUSSÃo}

Após a realização da análise de conteúdo, emergiram três categorias, quais sejam: 1) formação inicial em educação ambiental; 2) práticas em educação ambiental; 3) formação continuada e atualização sobre educação ambiental. A apresentação e a discussão dos resultados foram organizadas em subseções para facilitar a compreensão leitora, como se segue.

\section{Categoria 1 - Formação inicial em educação ambiental}

A formação inicial, desenvolvida em nível de graduação, mediante cursos de licenciatura em Pedagogia, habilita para a atuação no magistério na Educação Infantil e séries iniciais da Ensino Fundamental (SOUSA; MARQUES, 2019), portanto, é incumbido ao pedagogo um rol de disciplinas generalistas e específicas para a docência, que devem habilitá-lo para atuar na mediação da aprendizagem nas diversas áreas do conhecimento (FAOUR; CAMBA, 2019). A respeito desse percurso formativo, os entrevistados demonstraram insatisfação tanto no que concerne à ausência de discussão sobre a educação ambiental, quanto com o preparo para o cotidiano didático da sala de aula, que não condiz com a realidade discutida nos cursos formativos iniciais, conforme narrativa: “[...] a formação é voltada apenas para a prática de sala de aula, literalmente, e uma prática que nem sempre condiz com a realidade da gente, que, às vezes, chega a ser fantasmagórico" (P10).

P10 faz uma crítica acerca da formação inicial inferindo que esta não qualifica o professor para atuar na interface da teoria com a prática de maneira contextualizada. Portanto, o foco da formação inicial, ao contrário de trabalhar uma práxis articulada com a realidade sociocultural, centra-se nas práticas metodológicas e técnicas a serem aprendidas pelos fu- 
turos professores sem inter-relação com o contexto, como se a docência se tratasse de uma atividade mecânica e tecnicista (FRANCO, 2003; PINTO; BORGES, 2015).

Especificamente, no que remete à formação com vistas à discussão centrada na EA, dos 20 professores entrevistados, somente seis confirmaram a existência de uma disciplina voltada para esse escopo. No entanto, apesar de a disciplina estar presente no currículo do curso de formação inicial desses seis sujeitos, era ofertada de maneira opcional, logo, cabia aos graduandos decidirem se a priorizariam em detrimento de outras optativas. Por isso, somente dois professores escolheram se aprofundar nessa área, P14 e P16, que enunciaram, respectivamente: "Eu fiz como disciplina optativa na graduação"; "Na minha graduação já tinha na grade curricular como optativa e eu fiz".

Os outros quatro professores que tiveram a oportunidade de cursar a disciplina como optativa e não a escolheram, justificaram a falta de interesse. P6, por exemplo, ao ser indagada se seu curso ofertava disciplina sobre EA e se a cursou, respondeu objetivamente: "Sim, como optativa, mas não tive interesse de fazer" (P6).

Entre os outros 14 professores, que não tiveram oportunidade de cursar uma disciplina específica de EA, apenas P11, por sua vez, afirmou ter sentido falta: "na minha graduação não tive disciplina de educação ambiental, mas senti falta dessa opção para meu currículo acadêmico" (P11). Em suma, dos 20 professores entrevistados, somente dois cursaram disciplina específica de EA e três demonstraram esse interesse, pois os demais não consideravam a EA tão importante como as demais disciplinas.

O mais preocupante, todavia, não foi o fato de a maioria dos professores não ter a oportunidade de cursar uma disciplina específica sobre EA, mas o relato unânime de que esse conteúdo não era abordado de maneira interdisciplinar em outras disciplinas. Loureiro (2006) assevera a necessidade de desenvolver urgentemente uma consciência ambiental para assegurar a vida das futuras gerações no planeta Terra, inclusive, ressalta que a EA deve ser trabalhada na escola de forma crítica e interdisciplinar, pois objetiva a:

- busca da realização da autonomia e liberdades humanas em sociedade, redefinindo o modo como nos relacionamos com a nossa espécie, com as demais espécies e com o planeta;

- $\quad$ politização e publicização da problemática ambiental em sua complexidade;

- $\quad$ convicção de que a participação social e o exercício da cidadania são práticas indissociáveis da Educação Ambiental;

- preocupação concreta em estimular o debate e o diálogo entre ciências e cultura popular, redefinindo objetos de estudo e saberes;

- $\quad$ indissociação no entendimento de processos como: produção e consumo; ética, tecnologia e contexto socio-histórico; interesses privados e interesses públicos;

- busca de ruptura e transformação dos valores e práticas sociais contrários ao bem-estar público, à equidade e à solidariedade (LOUREIRO, 2006, p. 134).

Tendo em vista o panorama formativo que secundariza esses seis objetivos supramencionados, entende-se que a formação nesse campo do conhecimento, quando existe, se apresenta de modo fragilizado, demonstrando a pouca importância que a temática repre- 
senta para a formação de professores. Por consequência, de acordo com Guimarães (2007), as práticas docentes nesse viés tendem a ser imbuídas pelo autodidatismo por parte dos professores, perpetuando a ação fragmentada e fragilizada da EA, que acontece nas escolas de maneira isolada e a depender do interesse de cada educador em abordá-la ou não, resultando em ações "voltadas para o comportamento de cada indivíduo (aluno), descontextualizadas da realidade socioambiental em que a escola está inserida e do seu próprio projeto político-pedagógico [...]" (GUIMARÃES, 2007, p. 37).

Portanto, observa-se a irrelevância da EA nos cursos formativos de professores em Pedagogia. Incapaz de dar conta de uma formação completa, há a necessidade de ampliar a formação inicial de maneira continuada com vistas à minimizar as lacunas do curso superior (ARAÚJO; ESTEVES, 2017; MORORÓ, 2017; GENÚ, 2018; THERRIEN; AZEVEDO; LACERDA, 2017). A propósito, tais lacunas formativas refletem diretamente no modo que os docentes tratam essa temática em sala de aula, ou seja, na maneira como desenvolvem suas práticas pedagógicas, impossibilitando uma educação crítica e libertária (VASCONCELOS; FIALHO; LOPES, 2018), assunto que será discutido na seção seguinte.

\section{Categoria 2 - Práticas em educação ambiental}

Os docentes demonstraram nem sempre trabalhar a temática EA em sala de aula, mas reconhecem que esse é um assunto importante e necessário para a formação dos estudantes, sinalizando a necessidade de incluir a EA no currículo oficial de ensino (RAPOSO; FREITAS, 2019). No entanto, há o entendimento de que a organização curricular atual, mesmo que não contemple a EA no panorama de atividades obrigatórias, permite que o assunto seja trabalhado transversalmente: "[...] é uma coisa que se faz necessária, independentemente de ser obrigado ou não. Já deve fazer parte do currículo, até porque o meio ambiente, se a gente não tomar conta [...]" (P10).

P1, por sua vez, defende que a EA deve integrar a escolarização formal porque é valiosa para efetivar a formação integral do indivíduo: "é importante para a formação integral [...]. Pode ser vista como uma formação mais ampla, uma formação integral do aluno, uma formação comprometida com essa formação integral [...]" (P1). Pinheiro, Santos e Peluc (2017, p. 176) concordam com o relato ao lecionarem:

A intencionalidade do fazer educativo na EA transformadora permite aos sujeitos estabelecer relações entre a realidade e as questões políticas e ideológicas, amparados pela classe dominante, pelos valores impregnados nas relações humanas em sociedade, pelas dicotomias estabelecidas pelas desigualdades sociais, elevando, assim, o seu entendimento acerca das correlações entre tais premissas e as questões ambientais, tornando-os reflexivos e críticos na percepção do padrão de sociedade em que estão inseridos.

Esse entendimento é consoante ao escopo educativo definido pelos documentos legais que regem a educação brasileira, a exemplo da Base Nacional Comum Curricular (BNCC) que, ao definir as competências a serem dominadas pelos estudantes ao final da escolarização, determinou a formação para a cidadania, para o respeito aos direitos humanos e ao meio ambiente com vistas ao "agir pessoal e coletivamente com autonomia, responsabili- 
dade, flexibilidade, resiliência e determinação, tomando decisões com base em princípios éticos, democráticos, inclusivos, sustentáveis e solidários" (BRASIL, 2017, p. 10).

Na contramão do instituído pela BNCC, Klein e Pátaro (2008) acreditam que a formação considerada integral não é desenvolvida porque os currículos não a têm como prioridade, fazendo imperar nas escolas a educação de caráter tradicional e livresca. E foi exatamente o que se observou no que concerne à prática docente dos professores do Ensino Fundamental, majoritariamente centradas na utilização do livro didático para trabalhar as questões ambientais.

Excluindo-se práticas tradicionais de leitura do livro, resolução de exercícios e aulas expositivas, havia relatos de estímulos esporádicos para conscientização sobre a importância de destinar corretamente o lixo, fazer coleta seletiva e reciclagem. Esses foram os assuntos mais enfaticamente abordados, no entanto, sem uma sistematização ou um planejamento prévio, o que colabora para um ensino pouco didático e o fracasso escolar (PEREIRA; RIBEIRO, 2017).

Alguns professores afirmavam que conseguiam desenvolver uma docência que versava sobre a EA, mesmo que não mencionasse essa nomenclatura em suas aulas, e a justificativa era a falta de material didático disponível para tal. Tratavam de temas relacionados à manutenção da relação saudável do ser humano com o meio ambiente, incentivando os estudantes a manterem limpas as salas de aula, a escola e todos os ambientes que frequentam, bem como discutindo a respeito de possíveis danos causados quando não se zela o espaço que ocupa:

[...] Bem, a gente não trabalha, propriamente dita, com o tema Educação Ambiental. O que nós fazemos... A gente vai pegando fragmentos de alguma atividade, aquele conceito geral de sala. Manter a sala limpa. Não destruir as plantas, pois ao redor da nossa escola têm plantas. Não estar sujando o ambiente escolar e também o ambiente de todo o nosso território fora da escola. Trazer o pensar sobre o que pode acontecer se jogarmos um plástico, um papel na rua, o que pode acontecer com o nosso ambiente [...], o que vai acontecer quando chover (P7).

Outros docentes também afirmaram conversar com os alunos nesse sentido, partindo da realidade dos estudantes, como P6, que afirmou: “[...] Trabalho com eles para evitar o desperdício de água" (P6) e P8, que intervém quando nota que os alunos desperdiçam papel: “[...] Os meninos têm um hábito que quando erram, eles não apagam, eles arrancam a folha. Aí eu sempre chego e reclamo, digo para não fazer bolinha de papel, mas guardar para usar como borrão para a matéria da matemática [...]” (P8). Com base nesses relatos, nota-se que as ações consideradas pelos docentes como sendo na área da educação ambiental restringiam-se a conversas iniciadas pelos professores para conscientizar os alunos de maneira muito pontual e superficial (DIAS; NASCIMENTO; FIALHO, 2010).

P6, ao refletir e concluir que não ensejava destaque à EA em suas aulas, alegou que esse assunto deve ser tratado na disciplina de Ciências da Natureza: "[...] porque o pedagogo trabalha com as ciências da natureza em sala nessa parte que fala mais sobre a questão da poluição, da preservação do meio ambiente, do não desgaste da água [...]” (P6). Portanto, esse docente exprime que não valoriza a EA como caminho para garantir a for- 
mação integral dos estudantes (PERRENOUD, 2000), além de desacreditar do princípio da transdisciplinaridade instituído pelas Diretrizes Curriculares Nacionais, que aborda sobre os temas transversais (BRASIL, 1998), bem como pela LDB (BRASIL, 1996), segundo as quais a transdisciplinaridade deve promover a intersecção entre as diversas áreas do conhecimento com vistas à formação articulada e significativa do indivíduo de maneira integral.

Chamou atenção a dificuldade de os professores descreverem atividades pedagógicas práticas, como projetos, por exemplo, que objetivassem o envolvimento dos alunos com a EA, a partir da melhoria das condições encontradas nos seus contextos (BRASIL, 2007). Ainda que a comunidade estivesse historicamente emergida com a questão ambiental, já que o Jangurussu é conhecido como o bairro do lixão, não havia ênfase para o trabalho pedagógico com práticas dinâmicas e interativas para desenvolver a EA consciente (CARVALHO, 1998), o que permitiria não apenas a constituição de uma identidade com o território onde vivem, mas um engajamento consciente na corresponsabilização para a promoção de atitudes sustentáveis (FIALHO, MACHADO, SALES, 2014).

Mesmo que tenham sido apontadas algumas problemáticas ambientais pelos professores, como a reciclagem, o desperdício de água e a falta de higiene da sala e da escola, nem a proposta política pedagógica da escola nem o planejamento dos professores contemplavam a EA como pilar para a formação intelectual e humana dos alunos. Tampouco a EA era desenvolvida como tema transversal de suma importância articulando teoria e práticas educativas com esse viés, o que dificultava uma conscientização comprometida com a luta por políticas públicas (SUESCÚN, 2016; LIMA; AZEVEDO, 2019; BEGO, 2016; FLORENCIO; FIALHO; ALMEIDA, 2017) para a melhoria das condições de vida dos moradores locais e por mais justiça e igualdade social (LARA, 2016; TORRES, 2017). Afinal, a EA ultrapassa o repasse de conteúdo específico sobre o ambiente e fomenta uma compreensão que articula o homem ao ambiente, concebendo o espaço geográfico como um todo indissociável:

A educação ambiental é, portanto, levar as pessoas a repensar os valores que nos foram impostos por uma cultura de exploração da natureza e do homem, como se não fizéssemos parte desta natureza, e cujos resultados têm levado à degradação ambiental e milhões de seres humanos à miséria e fome (FERRAZ, 2004, p. 152).

Nota-se que os professores não trabalhavam valores com o objetivo de repensar o consumo desenfreado pela população, a exploração exacerbada do ambiente, a extinção de várias espécies de animais e vegetais e o prejuízo à vida humana no planeta. Tampouco partiam de questões ambientais para discutir as relações de trabalho, a exploração econômica, a desigualdade social e mecanismos de superação.

Importa mencionar, ante a ausência de relatos descritivos acerca de atividades diferenciadas com EA, as poucas experiências verbalizadas, por exemplo, a do P9, na aula de Matemática, que solicitou aos estudantes tampas de garrafas de plástico para a confecção de um jogo: “[...] quando trabalho a matemática com eles peço para os alunos trazerem tampinhas de garrafa [...]. Montamos um tabuleiro de dama, jogo que envolveu a reciclagem com os números, e, o melhor: o interesse dos alunos" (P9). Notemos que esse docente 
fez uso de um material reciclável para tornar o ensino da matemática mais atrativo, já que o concreto torna o ensino mais significativo e facilita a aprendizagem (CARVALHO; THERRIEN, 2009), conquanto, apesar de trabalhar com a reutilização de uma matéria reciclável, empreendimento importante para o desenvolvimento da educação ambiental (REIGOTA, 1995), em sua narrativa não ficou claro se ele problematizou junto aos estudantes sobre esse tema, não sendo possível concluir se esse docente abordou a educação ambiental inter-relacionada à Matemática.

\section{Categoria 3 - Formação continuada e atualização sobre educação am- biental}

A formação docente em exercício é um compromisso a ser firmado pela entidade fornecedora do serviço escolar, no caso da escola privada; ou pela instância pública, no caso das escolas mantidas pela iniciativa governamental, conforme explícito pela LDB (BRASIL, 1996), bem como, pelo Plano Nacional de Educação (2014-2024), que lista algumas possibilidades de promoção da formação continuada: palestra, grupo de estudo, pós-graduação latu e stricto sensu, rodas de conversa etc. (BRASIL, 2014). Conquanto, manter a classe docente sempre a par das transformações pode ser uma atividade dificultosa, tendo em vista o ritmo de trabalho dessa categoria, por isso, a formação em serviço ofertada pelas prefeituras municipais, incluídas na carga horária dos professores, é um avanço para a história da profissionalização da classe docente (JARDILINO; SAMPAIO, 2019). Apesar disso, foi relatado descontentamento com as formações, que não contemplam as necessidades docentes, conforme asseverado:

[...] quanto à formação oferecida pelo município é uma formação que, muitas vezes, não é suficiente porque [os professores] não se sentem contemplados. Acredito que se fosse feita uma pesquisa, muitos professores se posicionariam de forma negativa por exatamente não se sentirem contemplados (P1).

Esse docente acredita que as formações continuadas desenvolvidas pela prefeitura de Fortaleza são insuficientes por não dialogar com os anseios dos professores que, dessa maneira, não se sentem contemplados pelas atividades desenvolvidas nos ambientes formativos. Sobre esse aspecto, são muitos os estudos, resultados de pesquisas empíricas, que comprovam a realidade, conforme resultado do Estado da Arte desenvolvido por Fialho, Sousa e Freire (2020) acerca da literatura no campo da formação de professores disseminada pelas revistas do Norte e Nordeste brasileiro, que elucidaram, entre outros resultados, a insatisfação dos professores com relação às formações continuadas, pois há disparidade entre o que eles esperam das formações (orientações que subsidiem a prática) e o que é efetivado (socialização de conhecimentos que não dialogam com o cotidiano vivenciado). Há uma dicotomia entre a realidade da sala de aula e a teoria estudada nas formações, o que acarreta baixa qualidade da formação continuada de professores (LOURENÇO; SOUZA; INFORSATO, 2019) e prejuízo no aprendizado dos alunos, especialmente por não ser possível efetivar uma comunicação para envolver os educandos (FREITAS; FERREIRA, 2020).

Segundo Ferraz (2004), a educação para o meio ambiente é compreendida como a mais abrangente, por conceber o EA em sua totalidade, considerando os aspectos natu- 
rais, sociais, políticos, econômicos e culturais, numa abordagem holística das questões ambientais. Nesse sentido, um professor específico de Biologia, Geografia ou Ecologia não necessariamente será um educador ambiental, se este não empregar uma práxis pedagógica crítica e hermenêutica que trata o ambiente de maneira contextualizada com as demais interfaces sociais; na contramão, um pedagogo ou mesmo um professor de Matemática pode ser um educador ambiental, caso adote uma postura dinâmica que problematize os conhecimentos levantando questões macrossociais que tensionam atitudes responsáveis com o meio (FERRAZ, 2004).

A simples transmissão de informação, sem abertura à participação, por meio da sensibilização e engajamento na resolução, não surtirá efeitos significativos na mudança de atitudes individuais que possibilitem ensejar a transformação social, seja nas esferas locais, regionais, nacionais ou internacionais (SMYTH; HAMEL, 2016). É importante possibilitar que se desenvolva no indivíduo o sentimento de pertencimento à sua comunidade e localidade, bem como o entendimento de que todos são responsáveis pelo ambiente e afetados indiretamente pelas ações individuais e coletivas (FIALHO; MACHADO; SALES, 2014).

Especificamente no que concerne à formação para a abordagem da educação ambiental em sala de aula, todos os 20 docentes denunciaram a ausência dessa discussão nas formações. Por isso, assumiram ou o parco conhecimento adquirido a partir da iniciativa individual, como foi o caso de P1, que se sentiu motivada por se interessar pelo assunto: "Gosto muito do assunto e por isso já participei de palestra e eventos que envolvem a área" (P1); ou explicitaram o desconhecimento sobre o assunto, conforme discursado por P2:

[...] Não, assim, realmente, um estudo sobre isso eu não faço. Eu entendo que existe um cuidado com o ambiente, é educação ambiental, e sei mais ou menos como funciona [...]. Mas realmente curso, não tenho acesso, não fiz e nem na faculdade eu fiz, porque não busquei essa disciplina como optativa (P2).

À vista disso, percebe-se que esse docente entende superficialmente do que trata a educação ambiental, mas não buscou aprofundar-se sobre a temática, mesmo que tenha contado com a oportunidade de estudar a disciplina na formação inicial. De acordo com Mello e Souza (2000, p. 4):

A Educação Ambiental sofre com essas ambivalências, essas omissões teóricas e o singular fracionamento de significações, seu propósito é danificado. $\mathrm{O}$ objetivo de contribuir para a melhoria da consciência crítica, em relação à crise ecológica, registra o dano. Pulveriza e debilita a ação corretiva.

Para Klein e Pátaro (2008), esse é um fato comum e recorrente no magistério, pois os currículos focam em disciplinas consideradas mais relevantes e desconsideram outros assuntos também valiosos para a formação do indivíduo, como a educação ambiental e a formação para a cidadania (GUEDES, 2006). Dessa maneira, é enraizada a cultura escolar dos testes e das avaliações de áreas específicas (SOARES, 2012), e o professor, uma vez imerso nessa realidade, é influenciado por essa lógica e passa a selecionar quais áreas são mais importantes para a formação dos estudantes e quais podem ser dispensadas, como aconteceu com P2, que optou por não cursar a disciplina de educação ambiental no decorrer da graduação porque não a julgou relevante entre as demais disciplinas ofertadas em seu curso. 
Os cursos de formação continuada, não diferente, que priorizam os assuntos considerados mais relevantes, em especial matemática e português, desconsideram outras temáticas (RAPOSO; FREITAS, 2019), como as que discutem sobre os temas transversais, conforme explicitado por P10, ao afirmar que nunca teve uma formação continuada que tratasse sobre a educação ambiental. Cabendo-lhe a iniciativa de buscar aprofundar-se acerca do assunto mediante curso, pesquisas na internet e em revistas, P10 esclareceu que nenhum dos temas transversais foi abordado nos momentos destinados à formação em serviço que frequentou até o momento:

[...] quanto à atualização nessa área, cabe muito por necessidade nossa, como o curso da Fundação Demócrito Rocha, que é uma maneira da gente se atualizar. Porque se formos esperar pela prefeitura, isso não acontece. É vontade própria da gente mesmo com um artigo que sai na revista ou uma reportagem que sai no jornal; é buscando na internet, porque em outros ambientes ou no curso de formação semanal nada de temas transversais são contemplados (P10).

Ante esse esclarecimento, comprova-se, mais uma vez, a insuficiência das formações continuadas, ofertadas aos professores entrevistados no que concerne à EA. Tal deficiência amplia-se, inclusive, aos demais temas transversais elencados pela LDB, como a educação em direitos humanos e a instrumentalização para o exercício da cidadania, por exemplo, o que aponta para a desvalorização da formação integral e descompromissada com a atuação do indivíduo no seu meio (ALVES; FIALHO; LIMA, 2018). Salienta-se a necessidade de compreender que $\mathrm{o}$ ato de transformar a sociedade envolve conhecimentos múltiplos, conscientização, responsabilidade e compromisso social que sequer se restringem a mudanças locais, resultando em transformação em todas as esferas sociais onde o sujeito está inserido (PENELUC; SILVA, 2008).

\section{CONSIDERAÇões FINAIS}

A pesquisa partiu de inquietações sobre o que os professores do Ensino Fundamental entendiam por EA, o que aprenderam nas formações inicial e continuada acerca dessa temática e como desenvolviam as atividades didáticas com o mote de trabalhar a consciência ambiental nos seus alunos. Para descortinar tais indagações, realizou-se uma pesquisa com o objetivo de compreender o que os professores do Ensino Fundamental entendiam por educação ambiental e quais atividades pedagógicas desenvolviam para trabalhar esse campo do conhecimento. O estudo oportunizou refletir a respeito das particularidades que perpassam a formação de professores para a EA, tanto no que concerne à formação inicial quanto àquela desenvolvida em serviço, bem como. sobre a importância minorada ensejada à EA na escola.

Para alcançar o escopo, foi realizada pesquisa de abordagem qualitativa, do tipo estudo de caso, com 20 professores de uma Escola Municipal, localizada no bairro Jangurussu, Fortaleza-CE. O instrumento adotado para a coleta dos dados foi a entrevista, composta por indagações atinentes à formação inicial dos professores para a abordagem da educação 
ambiental em sala de aula, às práticas pedagógicas empreendidas com foco nessa área e acerca da relação entre a formação continuada e o trato desse tema transversal.

Averiguou-se que a formação inicial docente não instrumentaliza o professor para o desenvolvimento da educação ambiental, uma vez que quando essa disciplina é ofertada no curso superior, é de maneira optativa, cabendo ao licenciando decidir se deseja cursá-la ou não e, muitas vezes, ele opta por não aprofundar-se sobre essa temática por considerá-la menos relevante se comparada às demais disciplinas optativas. Somado a isso, também não há um trabalho interdisciplinar ao longo da graduação que possibilite desenvolver conhecimentos e habilidades didáticas para o trabalho educativo da EA na escola pelos futuros professores. Em consequência, o estudo acerca da EA é fragilizado e os formandos não conseguem desenvolver uma consciência a respeito da importância dessa temática para desenvolver uma consciência cidadã responsável comprometida com uma vida harmônica na interface com o ambiente.

A respeito da prática docente com ênfase na EA, demonstrou-se que os professores nem sempre trabalham com essa temática em sala de aula, reproduzindo a secundarização do nível de importância desse campo do saber em detrimento de outras disciplinas, como matemática e português. Mesmo que alguns professores considerem-na relevante para efetivar a formação integral dos estudantes e apontem para a necessidade de incluí-la como obrigatória no currículo oficial de ensino, tratam-na de maneira superficial, difusa, predominantemente com ações pontuais e fragmentadas.

O projeto político pedagógico da escola e as práticas docentes dos professores não ensejavam relevância à EA, mesmo que em contexto social caracterizado pelo acúmulo do lixo, poluição do solo e das águas, em decorrência do bairro ter sido o depósito de lixo de Fortaleza por anos. A EA era trabalhada a depender do interesse de cada educador que, por sua vez, ante a ausência de preparo e de material didático que tratassem sobre essa temática, restringia-se a discutir acerca dos cuidados para não poluir o ambiente, não mencionando o termo "educação ambiental”, tornando nítida, portanto, a desvalorização da EA.

$\mathrm{Na}$ perspectiva dos professores, a formação continuada ofertada pela prefeitura municipal era insipiente, pois não dialogava com as necessidades práticas dos professores e não trabalhava os temas transversais, desconsiderando-os nos encontros formativos. Dessa maneira, ficava difícil sensibilizar os docentes para a importância da EA para a formação integral do aluno, bem como, para o desenvolvimento de uma postura responsável e comprometida com a transformação da sociedade, valorizando o espaço geográfico e lutando por mais justiça social e qualidade de vida.

O estudo possui a limitação de poder ser generalizado por se tratar de uma pesquisa qualitativa de caso único, que investigou a realidade de uma única escola pública. No entanto, contribuiu por permitir conhecer a realidade pesquisada de maneira mais aprofundada, realçando as compreensões e as vivências dos professores, especificamente sobre a relação por eles estabelecidas com a EA em suas formações e em sala de aula, aclarando limites no fazer pedagógico para o ensino e a aprendizagem em EA. Sinalizou-se a necessidade de aprimorar a práxis em EA, que perpassa pela qualificação da formação docente, bem como, a relevância da realização de novas investigações que analisem contextos distintos para permitir a comparação de resultados e o aperfeiçoamento da EA, ampliando a visibilidade sobre essa temática. 


\section{REFERÊNCIAS}

ALVES, F. C.; FIALHO, L. M. F. Currículo na educação infantil: O que pensam os professores? Práxis educacional, v. 15, p. 251-272, 2019. Disponível em: http://periodicos2. uesb.br/index.php/praxis/index Acesso em: 18 jan. 2020.

ALVES, F. C.; FIALHO, L. M. F.; LIMA, M. S. L. Formação em pesquisa para professores da educação básica. Revista Tempos e Espaços em Educação, v. 11, n. 27, p. 285-300, 2018. Disponível em: https://seer.ufs.br/index.php/revtee/article/view/8582 Acesso em: 18 jan. 2020.

ARAÚJO, R. M.; ESTEVES, M. M. A formação docente, inicial e contínua, para o trabalho com adultos em Portugal: o olhar dos professores. Educação \& Formação, v. 2, n. 4, p. 18-35, 2017. Disponível em: https://revistas.uece.br/index.php/redufor/article/view/121 Acesso em: 12 abr. 2020.

BARDIN, L. Análise de conteúdo. Lisboa: Edições 70, 2006.

BEGO, A. Políticas públicas e formação de professores sob a perspectiva da racionalidade comunicativa: da ingerência tecnocrata à construção da autonomia profissional. Educação \& Formação, v. 1, n. 2, p. 3-24, 2016. Disponível em: https://revistas.uece.br/index.php/ redufor/article/view/98 Acesso em: 18 jan. 2020.

BRASIL. Ministério da Educação. Base Nacional Comum Curricular. Educação é a base. Brasília: MEC, 2017. Disponível em: http://portal.mec.gov.br/index.php?option=com_docman\&view=download\&alias $=79601$-anexo-texto-bncc-reexportado-pdf-2\&category_slug=dezembro-2017-pdf\&Itemid=30192. Acesso em: 6 abr. 2020.

BRASIL. Ministério da Educação. Educação ambiental: aprendizes de sustentabilidade. Brasília: SECAD/MEC, 2007. Disponível em: http://portal.mec.gov.br/secad/arquivos/pdf/ educacaoambiental.pdf Acesso em: 6 abr. 2020.

BRASIL. Resolução nº. 3, de 26 de junho de 1998. Institui as Diretrizes Curriculares Nacionais para o Ensino Médio. Brasília: MEC, 1998.

BRASIL. Lei no ${ }^{\circ}$ 13.005, de 25 de junho de 2014. Aprova o Plano Nacional de Educação e dá outras providências. Brasília: MEC, 2014.

BRASIL. Lei $\mathbf{n}^{\mathbf{0}}$. 9.394, de 20 de dezembro de 1996. Lei de Diretrizes e Bases da Educação Nacional. Brasília: MEC, 1996.

CARVALHO, A. D. F.; THERRIEN, J. O professor no trabalho: epistemologia da prática e ação/cognição situada - elementos para a análise da práxis pedagógica, Revista Brasileira 
de Formação de Professores, v. 1, n. 1, 2009, p. 129-147. Disponível em: http://www. facec.edu.br/seer/index.php/formacaodeprofessores Acesso em: 29 abr. 2020.

CARVALHO, I. C. de M. Em direção ao mundo da vida: interdisciplinaridade e educação ambiental/conceitos para se fazer educação ambiental. Brasília: IPÊ - Instituto de Pesquisas ecológicas, 1998.

CAVAlCANTE, I. N.; SOUZA, A. K. P.; ALMEIDA, N. M.; GOMES, M. C. R.; MATTA, M. A. Qualidade das águas subterrâneas entorno do lixão do Jangurussu - Fortaleza, Ceará - Brasil. Revista Águas Subterrâneas, 2011. Disponível em: https://aguassubterraneas. abas.org/asubterraneas/article/view/28121/18245 Acesso em: 11 abr. 2020.

DIAS, R. H. L.; NASCIMENTO, D. M.; FIALHO, L. M. F. A aprendizagem cooperativa no processo de ensino-aprendizagem: perspectivas do grupo de estudo do curso de licenciatura em geografia da UFC. Anais... XVI Encontro de Geógrafos Brasileiros - Porto Alegre. Porto Alegre, RS: AGB, 2010.

DINARTE, L. D.; CORAZZA, S. Espaço poético como tradução didática: Bachelard e a imagem da casa. Educação \& Formação, v. 1, n. 2, p. 135-148, 2016. Disponível em: https://revistas.uece.br/index.php/redufor/article/view/105 Acesso em: 11 abr. 2020.

FAOUR, I. C. S.; CAMBA, M. O diretor escolar e a formação dos professores na escola: compromisso social e político. Práxis Educacional, v. 15, n. 34, p. 284-301, 2019. Disponível em: https://doi.org/10.22481/praxisedu.v15i34.5630 Acesso em: 6 abr. 2020.

FERRAZ, J. M. G. Educação Ambiental e mudança de valores. In: HAMMES, V. S. (Org.). Proposta metodológica de macroeducação, 2. ed. São Paulo: Globo, 2004.

FIALHO, L. M. F. A vida de jovens infratores privados de liberdade. Fortaleza: UFC, 2015.

FIALHO, L. M. F.; MACHADO, C. J. S.; SALES, J. A. M. As correntes do pensamento geográfico e a Geografia ensinada no Ensino Fundamental: objetivos, objeto de estudo e a formação dos conceitos geográficos. Educação em Foco, v. 17, p. 203-224, 2014. Disponível em: http://revista.uemg.br/index.php/educacaoemfoco/article/view/432

FLORENCIO, L. R. S.; FIALHO, L. M. F.; ALMEIDA, N. R. O. Política de Formação de Professores: A ingerência dos Organismos Internacionais no Brasil a partir da década de 1990. Holos, v. 5, p. 303-312, 2017. Disponível em: http://www2.ifrn.edu.br/ojs/index. php/HOLOS/article/view/5757 Acesso em: 27 mar. 2020.

FRANCO, M. A. S. Pedagogia como ciência da educação. Campinas: Papirus, 2003. 
FREITAS, J. V.; FERREIRA, F. Educomunicação Socioambiental como estratégia pedagógica no Ensino Infantil. Educação \& Formação, v. 5, n. 14, 2020. Disponível em: https:// revistas.uece.br/index.php/redufor/article/view/1449 Acesso em: 11 abr. 2020.

FRIEDE, R.; REIS, D.; AVELAR, K.; MIRANDA, M. Coleta seletiva e educação ambiental: reciclar valores e reduzir o lixo. Educação \& Formação, v. 4, n. 11, p. 117-141, 2019. Disponível em: https://revistas.uece.br/index.php/redufor/article/view/924 Acesso em: 27 mar. 2020.

GENÚ, M. A abordagem da ação crítica e a epistemologia da práxis pedagógica. Educação \& Formação, v. 3, n. 9, p. 55-70, 2018. Disponível em: https://revistas.uece.br/index.php/ redufor/article/view/856 Acesso em: 18 jan. 2020.

GONÇALVES, R. M. P. A catação de lixo na (de) formação da criança como ser social. Tese, Universidade Federal do Ceará. Faculdade de Educação. Programa de Pós-Graduação em Educação Brasileira, Fortaleza, 2006.

GUEDES, J. C. S. Educação ambiental nas escolas de ensino fundamental: estudo de caso. Garanhuns: Ed. do autor, 2006.

GUIMARÃES, M. A formação de educadores ambientais, 3. ed. Ed. Papirus: Campinas-SP, 2007.

IZAIAS, F. M. C. Na rota do lixo: percursos de vida e trabalho de catadores do complexo de tratamento de resíduos sólidos do Jangurussu. Dissertação, Universidade Federal do Ceará. Faculdade de Educação. Programa de Pós-Graduação em Sociologia, Fortaleza, 2010. Disponível em: http://www.repositorio.ufc.br/handle/riufc/6355 Acesso em: 10 abr. 2020.

JARDILINO, J. R.; SAMPAIO, A. M. Desenvolvimento profissional docente: reflexões sobre política pública de formação de professores. Educação \& Formação, v. 4, n. 10, p. 180-194, 2019. Disponível em: https://revistas.uece.br/index.php/redufor/article/view/848 Acesso em: 10 abr. 2020.

KLEIN, A. M.; PÁTARO, C. S. de O. A escola frente às novas demandas sociais: Educação comunitária e formação para a cidadania. São Paulo: Ática, 2008.

LARA, A. M. Políticas de redução da desigualdade sociocultural. Educação \& Formação, v. 1, n. 3, p. 140-153, 2016. Disponível em: https://revistas.uece.br/index.php/redufor/article/view/118 Acesso em: 18 jan. 2020.

LIMA, A.; AZEVEDO, M. L. Processo de institucionalização da política nacional e estadual de formação docente: proposições e resistências no Paraná. Educação \& Formação, v. 4, n. 12, 2019. Disponível em: https://revistas.uece.br/index.php/redufor/article/view/1126 Acesso em: 5 abr. 2020. 
LIMA, J.; SANTOS, G. Valores, educação infantil e desenvolvimento moral: concepções dos professores. Educação \& Formação, v. 3, n. 8, p. 153-170, 2018. Disponível em: https://revistas.uece.br/index.php/redufor/article/view/275 Acesso em: 5 abr. 2020.

LIMA, W. Aprendizagem e classificação social: um desafio aos conceitos. Revista do ISEP/Programa de Mestrado em Ciências Pedagógicas, v. 3, 2004.

LOUREIRO, C. B. F. Complexidade e dialética: contribuições à práxis política e emancipatória em educação ambiental. Educação e Sociedade, v. 26, n. 93, p. 1.473-1.494, 2005. Disponível em: https://www.scielo.br/pdf/es/v27n94/a07v27n94.pdf Acesso em: 5 abr. 2020.

LOUREIRO, C. B. F. Crítica ao fetichismo da individualidade e aos dualismos na educação ambiental. Educar em Revista, n. 27, p. 37-53, 2006. Disponível em: https://revistas. ufpr.br/educar/article/view/6470 Acesso em: 5 abr. 2020.

LOURENÇO, R. S. S. L.; SOUZA, N. C. A. T.; INFORSATO, E. C. Formação continuada em serviço: relações entre seus aspectos fundamentais e as práticas instituídas. Práxis Educacional, v. 15, n. 32, p. 481-498, 2019. Disponível em: https://doi.org/10.22481/ praxis.v15i32.5065 Acesso em: 8 abr. 2020.

MELLO, E.; SOUZA, N. Educação Ambiental: dilemas da prática contemporânea. Rio de Janeiro: Thex, 2000.

MINAYO, M. C. S. Pesquisa Social: teoria, método e criatividade. Petrópolis: Vozes, 1994.

MORGADO, J. C. O professor como decisor curricular: de ortodoxo a cosmopolita. Revista Tempos e Espaços em Educação, v. 9, n. 18, p. 55-64, 2016. Disponível em: https:// seer.ufs.br/index.php/revtee/article/view/4964/4098 Acesso em: 7 abr. 2020.

MORORÓ, L. A influência da formação continuada na prática docente. Educação \& Formação, v. 2, n. 4, p. 36-51, 2017. Disponível em: https://revistas.uece.br/index.php/redufor/article/view/122 Acesso em: 18 jan. 2020.

PENELUC, M. C.; SILVA, S. A. H. Educação ambiental aplicada à gestão de resíduos sólidos: análise física e das representações sociais. Revista Entreideias, n. 14, p. 135-165, 2008. Disponível em: https://www.passeidireto.com/arquivo/68866012/gerenciamento-de-residuos-solidos-74/13 Acesso em: 5 abr. 2020.

PEREIRA, A.; RIBEIRO, C. S. A culpabilidade pelo fracasso escolar e a interface com os "problemas de aprendizagem" em discurso. Educação \& Formação, v. 2, n. 5, p. 95-110, 2017. Disponível em: https://revistas.uece.br/index.php/redufor/article/view/138 Acesso em: 18 jan. 2020. 
PERRENOUD, P. Dez novas competências para ensinar. Porto Alegre: Artmed, 2000.

PINHEIRO, B. C.; SANTOS, C.; PENELUC, M. A educação ambiental na formação de professores de química da UFBA. Educação \& Formação, v. 2, n. 4, p. 181-203, 2017. Disponível em: https://revistas.uece.br/index.php/redufor/article/view/129 Acesso em: 18 jan. 2020.

PINTO, B. C. T.; BORGES, J. L. C. Uma atividade de educação ambiental em espaço não formal: potencialidades do uso de bacias hidrográficas. Disponível em: Revista Tempos e Espaços em Educação, v. 8, n. 16, p. 109-124, 2015.

RAPOSO, E. O.; FREITAS, N. M. S. Coletivo de estudos, formação e práticas em educação para o desenvolvimento sustentável: itinerários de uma formação. Revista Exitus, v. 9, n. 2, p. 322-350, 2019. Disponível em: http://dx.doi.org/10.24065/2237-9460.2019v9n2ID865 Acesso em: 7 abr. 2020.

REIGOTA, M. Meio ambiente e representação social. São Paulo: Cortez, 1995.

SMYTH, E.; HAMEL, T. The history of initial teacher education in Canada: Québec and Ontario. Educação \& Formação, v. 1, n. 1, p. 88-109, 2016. Disponível em: https://revistas.uece.br/index.php/redufor/article/view/93 Acesso em: 18 jan. 2020.

SOARES, G, L. A formação do cidadão no ambiente escolar: da conscientização à intervenção na própria realidade. Porto Alegre: Pampa, 2012.

SOUSA, E.; MARQUES, E. O processo de constituir-se professor na relação objetividade-subjetividade. Educação \& Formação, v. 4, n. 11, p. 82-96, 2019. Disponível em: https:// revistas.uece.br/index.php/redufor/article/view/841 Acesso em: 10 abr. 2020.

SUESCÚN, M. Políticas públicas educativas en el contexto social colombiano de la década de los 70 del siglo XX. Educação \& Formação, v. 1, n. 1, p. 65-87, 2016. Disponível em: https://revistas.uece.br/index.php/redufor/article/view/92 Acesso em: 29 abr. 2020.

THERRIEN, J.; AZEVEDO, M. R.; LACERDA, C. A racionalidade pedagógica nos processos de mediação à produção de sentidos e de aprendizagem aos saberes. Educação \& Formação, v. 2, p. 186-199, 2017. Disponível em: https://revistas.uece.br/index.php/redufor/article/view/166 Acesso em: 29 abr. 2020.

TORRES, J. M. Exclusión social y educación superiora: la respuesta pedagógica. Educação \& Formação, v. 2, n. 6, p. 3-16, 2017. Disponível em: https://revistas.uece.br/index. php/redufor/article/view/157 Acesso em: 18 jan. 2020.

VASCONCELOS, J. G.; FIALHO, L.; LOPES, T. M. Educação e liberdade em Rousseau. Educação \& Formação, v. 3, n. 8, p. 210-223, 2018. Disponível em: https://revistas. uece.br/index.php/redufor/article/view/278 Acesso em: 18 jan. 2020. 
YIN, Robert. Estudo de caso: planejamento e métodos. Porto Alegre: Bookman, 2001.

\section{DAdOS DAS AUTORAS}

\section{Lia Machado Fiuza Fialho}

Doutora em Educação. Professora do Programa de Pós-graduação em Educação da Universidade Estadual do Ceará. Ceará/CE-Brasil. lia_fialho@yahoo.com.br

\section{NaARa Campelo Rodrigues}

Graduada em Saneamento Ambiental e em Pedagogia pela Universidade Estadual do Ceará. Ceará/CE-Brasil.naaracampelo@gmail.com

\section{Francisca Genifer Andrade de Sousa}

Doutoranda em Educação pelo Programa de Pós-Graduação em Educação da Universidade Estadual do Ceará. Ceará/CE-Brasil. geniferandrade@yahoo.com.br

Submetido em: 6-5-2020

Aceito em: 19-10-2020 